\title{
Issues in business rates and revaluation for 2005
}

Received. 21 March 2005

\begin{abstract}
David Hudson
has 28 years' experience in the valuation of property for business rates and has worked in both the public and private sectors. He spent 13 years in the Valuation Office, including three years at its head office, where he advised local valuation officers on the principles and practice of rating valuation. He entered private practice in 1989, and is now the director of business rates at LSM Partners, a London-based property consultancy, advising both public and private sector clients throughout the UK on minimising rate bills.
\end{abstract}

\begin{abstract}
This paper deals with the principles and practice of valuation for business rates and explains the background to the rating system in England, Scotland and Wales. It covers the basis on which rateable values are assessed, the calculation of the rate bill and how the bills are adjusted for transitional relief. It also explains the way in which the Valuation Office and Scottish Assessors prepare the valuations, the nature of the evidence used and how it is collected and analysed. It explains how appeals against the original revaluation assessments are considered and negotiated, and gives some guidance on when further appeals might be made. It also considers challenges against rate demands, outlines some of the reliefs that may be available and gives guidance on rate liabilities for empty or part-empty premises. This paper will be of interest to finance directors, facilities managers, office managers and anyone responsible for the payment of rates, as it provides guidelines on how the bills may be minimised.
\end{abstract}

\section{Keywords:}

business rates, revaluation, rateable value, transitional relief, appeal, minimising rate liability

\section{OVERVIEW OF THE BUSINESS RATES SYSTEM}

The 2005 business rates revaluation is now taking place, and companies will be seeing the effects of new rate bills from 1 April. Business rates are often seen as a complex subject and difficult to understand, but the basis of the tax is quite straightforward.

The business rate is a tax on the occupation of commercial property and affects all businesses, large or small, in the UK. At its simplest, the rate liability for any premises is calculated by multiplying the rateable value by the uniform business rate:

Rates payable $=$ Rateable value $(\mathrm{RV}) \times$ Uniform business rate $(\mathrm{UBR})$ 


\section{Appeals evidence}

\section{Access to valuations}

date and require little adjustment will carry greatest weight when considering the evidence.

Any valuation is of course a matter of opinion (based on evidence), and valuations for rating purposes are therefore subject to appeal to ensure fairness. As part of any appeal, the parties, being the valuation officer or assessor and the ratepayer or its agent, consider the rent of the premises and the extent to which it supports the valuation. They also consider evidence from rents of comparable premises in the area and the RVs on those properties.

The debate over fairness versus accuracy in rating valuation has been the subject of much litigation and comment, and discussion could fill several pages. The integrity of the rating system could be called into question if occupiers of different premises were not treated equally. The valuation officer therefore cannot expect to avoid challenges against his valuations simply by adopting very conservative levels of value, although many are expected to try.

Other methods of assessment are used to arrive at a valuation for those properties that are owner occupied and with no comparable rental premises in the area. In the private sector this will usually involve looking at receipts or other measures of trading potential. For example, the valuation may reference the throughput of petrol at a filling station or the volume of beer, wine and spirits sales for a public house. In the public sector many buildings, including local authority leisure centres, are valued using the rebuild cost.

\section{PUBLISHING THE VALUATIONS}

Once calculated all RVs are entered into a document called a rating list (in England and Wales), or a valuation roll (in Scotland). The lists for England and Wales can be viewed at www.voa.gov.uk and for Scotland at www.saa.gov.uk. Detailed valuations of most premises in England and Wales are also available on the website and occupiers can view and check the site for factual accuracy. Hard copies of these valuations will have been sent to occupiers in October 2004. The website does not, however, hold details of valuations made by reference to receipts or construction costs, and occupiers of these premises will not have received valuations in the post.

\section{REVALUATION CHANGES}

An initial appraisal of the valuations in England shows there will be an average increase in RVs on revaluation of 17.9 per cent. The corresponding average increase figures for Scotland and Wales are 13.3 per cent and 12.5 per cent respectively.

\section{Retail}

Closer analysis of the figures in the retail sector shows considerable disparity in valuations. Some valuations in Oxford Street have fallen by as much as 50 per cent, while others have increased by 60 per cent. The rateable values of many shops in Bluewater have 
Wide variation in impact

Rateable value limits increased by more than 150 per cent, and in the Trafford Centre one shop has seen an increase of over 300 per cent.

\section{Leisure}

Pubs, bars and restaurants vary significantly according to property type and location. Across this sector average increases are in the order of 20-25 per cent but some premises show increases of as much as 500 per cent. With valuations closely related to turnover, it would be expected that those premises trading successfully would show the largest increases.

Theatres are less varied, with those in the West End showing a remarkably consistent increase of 35 per cent, suggesting the Valuation Office has adopted a general increase for this category rather than looking at individual valuations.

It is evident from the comments above that the average increases quoted by the government mask wide variations in rate bills and are not at all helpful in predicting the effect of the revaluation on any particular occupier. Property managers will notice substantial differences across large portfolios, especially where units are spread across different regions.

\section{UNIFORM BUSINESS RATE}

The UBR is fixed by the government, and increases annually by the rate of inflation. Small businesses in England and Scotland will pay a lower UBR. The figures for 2005-2006 are shown in Table 1.

\section{Small business relief}

Small businesses are defined as those occupying only one property, with a RV below $£ 15,000$ in England ( $£ 21,500$ for London) or $£ 11,500$ in Scotland. Businesses with more than one property are included if the aggregate of the RVs of all premises occupied falls within the limits stated above. Small businesses pay rates at the 'small business' level shown in Table 1.

Premises occupied by small businesses may also be eligible for additional relief if they have an RV below $£ 10,000$ in England or $£ 11,500$ in Scotland. This relief is given as a percentage deduction from the rate bill, starting at 50 per cent for the smallest premises and reducing on a sliding scale towards the threshold.

\section{TRANSITIONAL RELIEF}

The purpose of revaluation is to revise values corresponding to movements in property rents. Those sectors thriving and able to

Table I: UBR for 2005-2006

\begin{tabular}{lll}
\hline & Large premises & Small businesses \\
\hline England & $42.20 \mathrm{p}$ & $41.50 \mathrm{p}$ \\
Scotland & $46.55 \mathrm{p}$ & $46.10 \mathrm{p}$ \\
Wales & $42.10 \mathrm{p}$ & $4210 \mathrm{p}$ \\
\hline
\end{tabular}




\section{No relief in Wales}

pay increased rents will bear a higher proportion of the tax burden, while struggling sectors will expect to see their tax reduced.

The Welsh Assembly has taken a view that it should not dilute the redistributive effect of the revaluation. As a result, Wales will not have a transitional scheme in place for the 2005 revaluation. This will make the calculation of rate bills much simpler while reducing administrative costs.

In England and Scotland, however, there will be a complex system of transitional adjustments that need to be applied when calculating the rate bill. Therefore the full effect of the revaluation will not be felt immediately in every case.

The relief is aimed at softening the impact for those businesses whose bills stand to increase the most. The retail sector is generally the worst hit by this revaluation and retailers lobbied heavily for the retention of transitional relief, so the introduction of the scheme is good news for the sector.

\section{The scheme in England}

\section{How the scheme works}

The scheme is quite complex, with separate provisions for 'large' and 'small' properties. Both are defined by reference to their RVs, with different thresholds for premises inside and outside the Greater London area. Within London 'small' properties are defined as those with an RV below $£ 21,500$; outside London the threshold is $£ 15,000$.

\section{How the rate bill is adjusted}

Under the proposed arrangements, the previous year's rate bill is adjusted by inflation and then the maximum increase or reduction is fixed to a percentage, which changes year by year. Details for increases are set out in Table 2 .

The rate bill will be either the figure resulting from the application of the percentage in Table 2, or the calculation of RV multiplied by the UBR, whichever is the lower. This is perhaps best illustrated by an example.

\section{Example: Rate increase}

Figure 1 shows the effect of transitional relief on a property where the RV has increased by 50 per cent from $£ 100,000$ to $£ 150,000$ as a result of the revaluation. Without transitional relief the 2005-2006 rate bill would be $£ 63,300$ and in 2006-2007 the bill would be

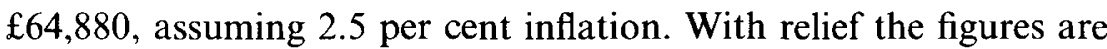

Table 2: Maxımum increase in annual rate bills (after inflation)

\begin{tabular}{lccccc}
\hline & 2005-2006 (\%) & 2006-2007 (\%) & 2007-2008 (\%) & 2008-2009 (\%) & 2009-2010 (\%) \\
\hline Large properties & 12.5 & 17.5 & 20 & 25 & No limit \\
Small properties & 5.0 & 7.5 & 10 & 15 & No limit \\
\hline
\end{tabular}




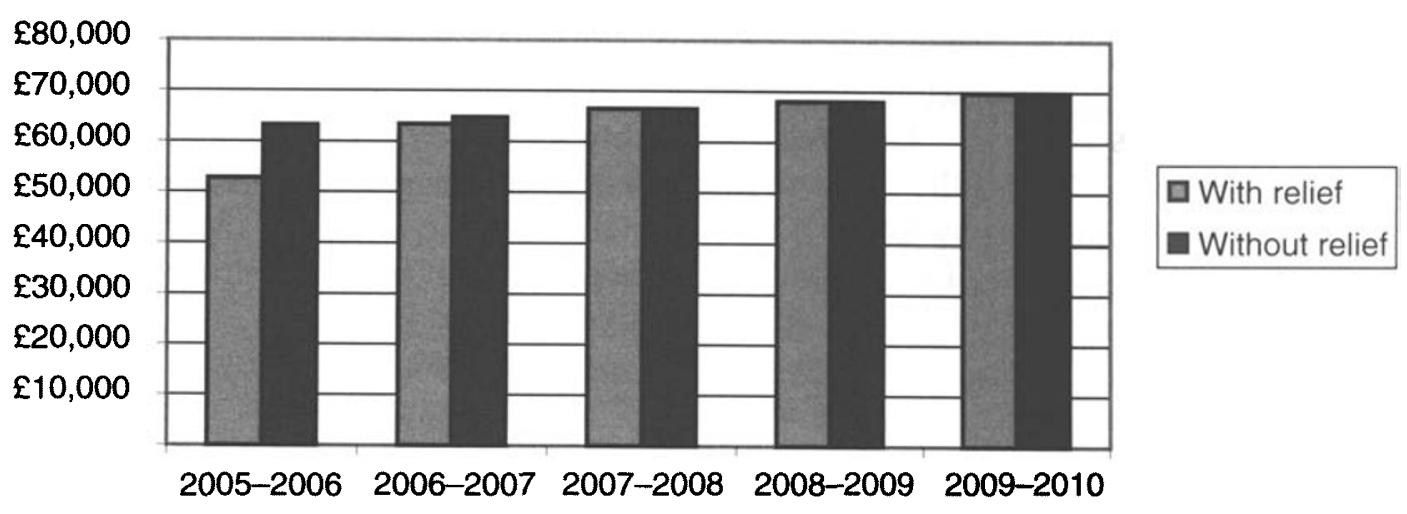

Figure 1: Example of rate increase

\section{Application to reduced liability}

reduced to $£ 53,580$ and $£ 63,330$ respectively. In $2007-2008$ the transitional scheme has worked through in this particular case and there is no relief. With a greater RV increase, the transitional scheme would take longer to work through.

The bad news is that relief for the increased rate bills will be paid for by staging the full benefit for those whose bills have been reduced. Therefore, both increases and reductions will be phased in by the transitional arrangements. Details for reductions are set out in Table 3. The rate bill will be either the figure resulting from the application of the percentage in Table 3, or the calculation of RV multiplied by the UBR, whichever is the higher this time.

\section{Example: Rate reduction}

Figure 2 shows the effect of a transitional charge on a property where the RV has been reduced from $£ 100,000$ to $£ 70,000$. In the absence of a scheme the bill would drop to $£ 29,540$ in $2005-2006$, $£ 30,275$ in $2006-2007$ and $£ 31,035$ in 2007-2008. Under the transitional scheme the corresponding figures will be $£ 40,900$, $£ 36,650$ and $£ 32,325$. There is no transitional adjustment from 2008-2009 in this particular example, and increases follow inflation from that year.

\section{The scheme in Scotland}

In Scotland the scheme works differently. Increases in the first year are capped at 12.5 per cent and decreases at 10 per cent, after making the inflation adjustment. The transitional adjustment in 2005-2006 is the difference between the bill with the cap applied and the unadjusted charge (calculated at RV multiplied by the UBR).

Table 3: Maximum reduction in annual rate bills (after inflation)

\begin{tabular}{llllll}
\hline & 2005-2006 (\%) & 2006-2007 (\%) & 2007-2008 (\%) & 2008-2009 (\%) & 2009-2010 (\%) \\
\hline Large properties & 12.5 & 12.5 & 14 & 25 & No limit \\
Small properties & 30.0 & 30.0 & 35 & 60 & No limit \\
\hline
\end{tabular}




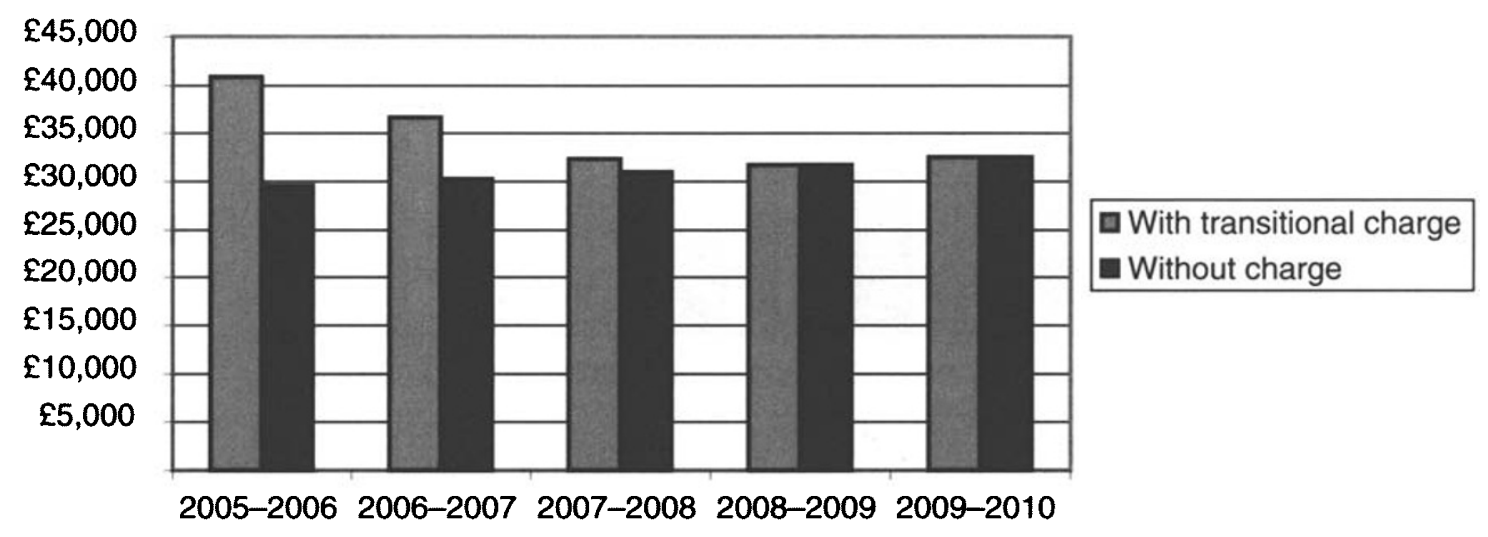

Figure 2: Example of rate reduction

\section{Subsequent years}

The amount of the transitional adjustment is then reduced by one-third in 2006-2007 and a further one-third (of the original amount) in 2007-2008, so that no premises will be subject to transitional adjustments in the fourth and fifth years.

In Scotland there is no distinction between large and small premises for the purposes of transition.

\section{Example: Rate increase}

Figure 3 shows the effect of transitional relief on a property in Scotland experiencing an increase in RV from $£ 100,000$ to $£ 150,000$ as a result of the revaluation. Relief is phased out by equal instalments over the first three years, with no relief in years four and five.

\section{Example: Rate reduction}

The phasing in of reductions for premises in Scotland works in much the same way, in reverse, with any reduction of more than 10 per cent in real terms being phased in by equal instalments over the first three years. Figure 4 shows the effect of the transitional charge on the rate bill of premises showing a reduction in $\mathrm{RV}$ on revaluation from $£ 100,000$ to $£ 70,000$.

Thus, different rules apply to the calculation of rate bills in England, Scotland and Wales, with further variations in England

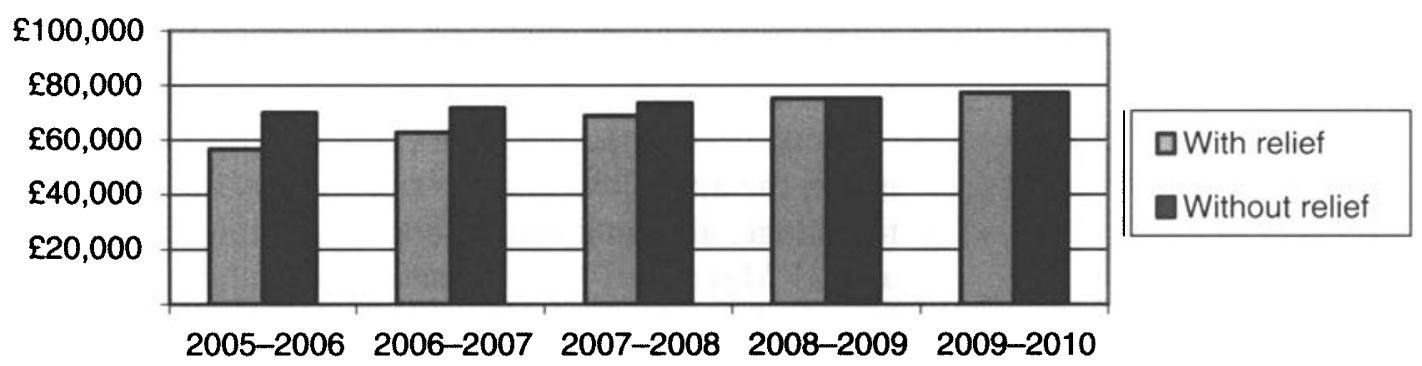

Figure 3: Example of rate increase in Scotland 


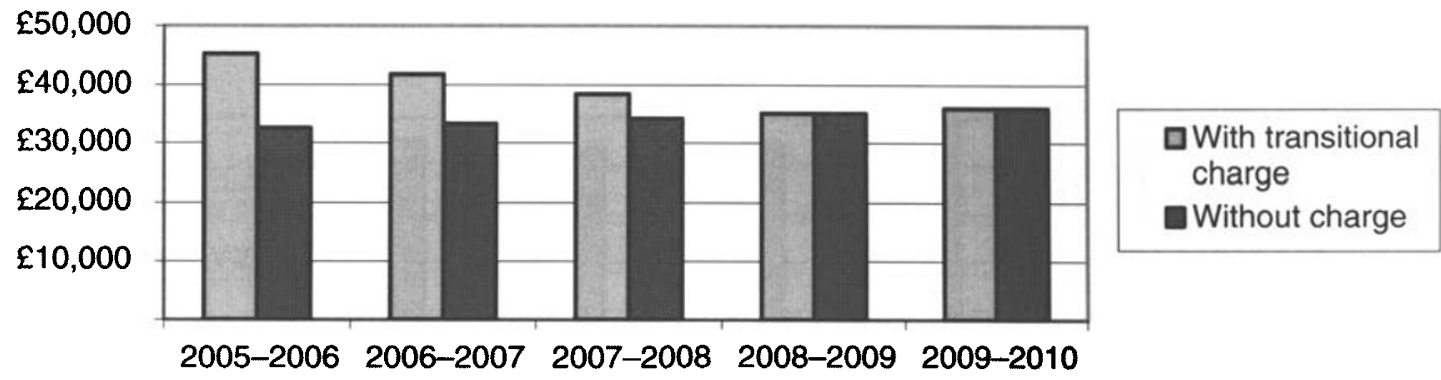

Figure 4: Example of rate reduction in Scotland

\section{Rent returns}

\section{Limitation on appeal rights}

for properties inside and outside London. It is clear from the above examples that calculation of annual rate payments can be complex and finance directors will need specialist advice to prepare reliable budgets.

\section{MINIMISING LIABILITY}

Many ratepayers are aware of the opportunities to appeal the RV of their premises following a revaluation. But there are many aspects of the rating system that need to be taken into account in minimising rate payments, and an experienced rating surveyor will be able to advise on all aspects of liability.

\section{Provision of information}

The minimising of rate liability starts long before the initial valuations have been made, with the completion of the rent return forms. It is important that forms show full details of all concessions negotiated at the commencement of the lease and identify any special circumstances that have been reflected in rent review settlements, as this will influence the valuation officer's analysis.

This is especially important where premises are unusual or where there are no similar properties nearby - in these cases, rent passing for the property may be the only evidence of value.

\section{Appeals}

An appeal against the RV may be made by an interested party, usually the owner or occupier of the premises.

There are a number of important changes to the appeals regulations proposed for the 2005 revaluation. The most significant changes are as follows.

- Under the previous arrangements an appeal could only lead to a recalculation of the bills from the beginning of the rate year in which the appeal was made. For the 2005 revaluation this is due to change, and an appeal made at any time between 1 April 2005 and 31 March 2010 can result in recalculation of the charges from 1 April 2005.

- Appeals will be limited to one per interested party. Further appeals will only be permitted where the valuation officer or 


\section{Evidence to support appeals}

\section{Changes affecting value}

assessor has altered the RV between April 2005 and March 2010 (perhaps because of alterations to the property) or where circumstances have changed such that the value of the property would be affected. Each change will give a right to one further appeal for any interested party.

- The rent passing for the premises at the date the appeal is made must be given on the appeal form.

These changes will substantially affect the tactics of the appeal process, and more careful consideration will need to be given to whether and when to appeal than has previously been the case.

\section{Appeals against the 1 April 2005 valuation}

A ratepayer who wishes to appeal against the 1 April 2005 valuation will have to show that the RV is excessive. This can be done by producing evidence of rents fixed for comparable premises around the April 2003 valuation date. As agreements are reached the importance of direct rental evidence reduces, and the agreed valuations add to the body of evidence against which any appeal is tested.

It is irrelevant whether the rate bill has increased or decreased as a result of the revaluation - even if the bill is reduced further savings may still be possible as a result of a successful appeal.

\section{Appeals for changed circumstances}

A reduction in $R V$ might be negotiated when there is a change of circumstance; there are many varied situations where this can occur. But there is a strict framework within which such changes may be considered.

Purely economic changes will not lead to a reduced valuation, but other changes that directly affect the demand for premises may be taken into account. Appeals have been successfully made in respect of the foot-and-mouth epidemic and the attack on the World Trade Center, when it has been possible to show that trade has been adversely affected because of reduced foreign tourism. More obvious instances that might affect the value of premises are:

- a new bypass that directs traffic away from an established petrol station

- the opening of a new gymnasium and health spa close to an existing fitness centre

- building works on adjacent premises

- a new one-way system affecting access to part of a town centre

- a new out-of-town retail centre close to an established town

- closure of a public car park serving customers of the premises

- changes in trading patterns following pedestrianisation of a town centre.

It is therefore important to keep the RV under constant review, and to take any opportunity to make an appeal if circumstances occur 
Backdating increases

\section{Refurbishment and repair}

that adversely affect rental value. The valuation officer or assessor will also revise valuations from time to time where circumstances change. Ratepayers should be aware that improvements in the locality might be grounds for increasing the valuation. Under the new regulations the valuation officer or assessor will be able to backdate increases into earlier rate years, so provisions may need to be made in the accounts for possible future increases where changes have made the premises more valuable.

\section{Unoccupied premises}

Rates are generally payable for unoccupied premises at 50 per cent of the level applied to occupied properties, subject to a number of exemptions and exclusions. The principal ones are:

- no unoccupied rates are payable in the first three months following vacation (or in the case of new premises, completion)

- listed buildings are exempt from unoccupied rates

- industrial premises and premises used for storage are also exempt from unoccupied rates.

Where premises are vacant during the course of refurbishment or held vacant pending demolition, it may be possible to have the RV reduced to a nominal level, thus avoiding the unoccupied rate charge (of 50 per cent).

Premises in disrepair are subject to special rules for rating valuations, and it is assumed that a landlord of the premises would put them into repair rather than accept a reduced rent. Therefore, in seeking nominal valuations for premises awaiting refurbishment it will be necessary to show that the works required to make the premises usable are not repairs, or that they would be so expensive that a reasonable landlord would not do them.

\section{Part-occupied property}

Where premises are partly occupied it may be possible to have the $\mathrm{RV}$ split between the occupied and unoccupied parts so as to obtain relief on the vacant areas. In order to obtain a split of the assessment it is necessary for the premises to be capable of separate occupation.

Where a division is not possible and the vacation is only temporary, the council has a discretionary power to grant relief on the unoccupied part. This is based on an apportionment of the RV between the occupied and unoccupied areas. An application must be made to the council, which, if it is willing to grant relief, will ask the valuation officer to apportion the valuation.

\section{Rate bill and transitional errors}

Although appeals cannot be made against the UBR, bills may be subject to challenge for calculation errors. This is a complex area of rating law and it is not possible to give a definitive list of 


\section{Billing errors}

\section{Late demands}

circumstances where it may be possible to challenge bills. But the following case studies illustrate the benefits of giving careful consideration to all aspects of the rate valuation and billing process.

The complexities of the transitional regulations are such that even the sophisticated computer programs used by local authorities do not always produce the correct answers. This can especially occur when there are many changes to the RV, particularly if more than one assessment is involved, for example, when existing premises are split or are merged with adjacent premises.

\section{Case study - Transitional errors \\ Study 1}

A television company located in London initially occupied a studio which comprised four floors in one wing of a large building. It subsequently reduced its occupation to only two floors and later the company took over a floor in a different wing. It then expanded into the whole of that wing. Each time there was a change in occupation the valuation officer had to alter the RVs of the various parts of the building occupied.

As a result the council had to recalculate the transitional relief, and in the course of the alterations it made a number of errors. Consequently, the TV company overpaid its rate bill by more than $£ 870,000$ over a period of four years. The council initially refused to accept the error, but after detailed negotiations the overpayment was refunded, with interest.

\section{Study 2}

A ratepayer was in occupation of part of a large building, and obtained a division of the assessment effective from 1 April 2000 to claim unoccupied relief. The valuation of the premises was substantially reduced on revaluation in 2000 and the bill was therefore subject to a transitional charge. Special provisions apply to the calculation of transitional arrangements where the valuation is split on the first day following a revaluation.

The local authority applied the transitional arrangements incorrectly and overcharged the ratepayer. A review of liability under a rates audit brought the error to light and a successful claim was made for a refund of approximately $£ 200,000$.

\section{Case study - Delayed billing}

Study 3

A landlord in Liverpool let out several premises on licences. The premises were all separately valued and the council demanded rates from the licensees. Following difficulties in collecting the rates spanning several years the council decided that it would seek payment from the owner. Payments were sought going back over a number of years.

The landlord company challenged the council on the grounds 


\section{Professional advice}

that it had given the rights of occupation to the licensees and was therefore not liable. It further argued that the council had acted unreasonably in demanding rates several years after they were due. The landlord, not being in occupation and not having received demands in the years concerned, had reasonably assumed the occupiers had paid the rate bills.

The matter was heard in the magistrates' court, and it was found that the landlord was liable to pay but that the council could not recover historic arrears. This resulted in the demands being reduced by approximately $£ 100,000$.

\section{Rates audit}

For large organisations it is well worth commissioning an audit of past liability to identify any possible overpayments. This is a highly specialised field of expertise and involves a detailed examination of back-dated bills to ensure that the rates have been properly calculated.

\section{GETTING THE RIGHT ADVICE}

With the limitation on appeals it will be all the more important for occupiers to ensure they are getting the right advice. There will be no second chance to correct mistakes.

The past few years have seen much comment about unqualified and unregulated rating advisers. Many property managers have become sceptical about the value of the advice available.

Those requiring advice, or those who are unsure of how the changes are likely to affect them, should feel confident in speaking to qualified surveyors who can provide guidance through the approaching revaluation minefield. If in doubt ratepayers should ask advisers if they are members of the Royal Institution of Chartered Surveyors (RICS) or Institute of Revenues Rating and Valuations (IRRV). Both organisations have rigorous professional standards and rules of conduct specifically referring to business rates advice.

\section{(C) LSM Partners}

